\title{
Clinicopathological Significance of Overall Frequency of Allelic Loss (OFAL) in Lesions Derived from Thyroid Follicular Cell
}

\author{
Monika Migdalska-Sęk ${ }^{1}$ (D ) Karolina H. Czarnecka ${ }^{1} \cdot$ Michał Kusiński $^{2} \cdot$ Dorota Pastuszak-Lewandoska $^{1}$. \\ Ewa Nawrot ${ }^{1} \cdot$ Krzysztof Kuzdak $^{2} \cdot$ Ewa Brzeziańska-Lasota ${ }^{1}$
}

Published online: 11 February 2019

(c) The Author(s) 2019

\begin{abstract}
Background Loss of heterozygosity (LOH) and microsatellite instability (MSI) are frequent molecular events in thyroid tumor etiopathogenesis occurring in several chromosomal critical areas, including 3p12-25.3, 7q21-31, 10q22-24, and 15q11-13, with loci of tumor suppressor genes.

Objective We evaluated the usefulness of LOH/MSI as a diagnostic/prognostic biomarker in lesions derived from thyroid follicular cells: follicular thyroid carcinoma (FTC); follicular adenoma (FA), papillary thyroid carcinoma (PTC), and nodular goiter (NG).

Methods We performed allelotyping (GeneMapper Software v. 4.0.) of ten microsatellite markers linked to the 1p31.2, $3 \mathrm{p} 21.3$, 3p24.2, 9p21.3, 11p15.5, and 16q22.1 region on DNA from 93 primary thyroid lesions then evaluated the LOH/ MSI frequency and overall frequency of allelic loss (OFAL).

Results We found regions with significantly increased frequency of LOH/MSI for specific histotypes: the 3p24.2 region for FA and 1p31.2 for FTC. LOH/MSI in 3p21.3 was significantly elevated in PTC and FTC. LOH/MSI in 3p21.3 was increased for small size tumors $(\mathrm{T} 1 \mathrm{a}+\mathrm{T} 1 \mathrm{~b})$, tumors with no regional lymph node involvement $(\mathrm{N} 0+\mathrm{Nx})$, American Joint Committee on Cancer (AJCC) stage I tumors, and tumor diameter (Td) < $10 \mathrm{~mm}$; in 1p31.2 for T2-3, N1, stage II-IV, and Td 10-30 mm; in $11 \mathrm{p} 15.5$ for $\mathrm{T} 2-3, \mathrm{~N} 1$, stage II-IV, and Td $>30 \mathrm{~mm}$. OFAL values were significantly higher in younger patients $(<40$ years), in men, in those with T2-3 stage tumors, in those with increased Td, and in FA and FTC compared with NG and PTC.

Conclusions We confirmed the occurrence of LOH/MSI in 3p21.3 at an early stage of tumorigenesis and mapped 1p31.2 and 11 p15.5 as characteristic for advanced-stage tumors. The results of our study may enable consideration of OFAL, defined as LOH/MSI coincidence in various chromosomal regions, as a tumor progression marker. OFAL values were significantly higher in follicular neoplasms (FA and FTC) than in PTC or NG; hence, increased OFAL values can be regarded as a characteristic feature of the follicular phenotype.
\end{abstract}

\section{Introduction}

The high prevalence of thyroid carcinomas ranks this disease in first place among all endocrine malignancies worldwide. The incidence of thyroid carcinoma continues to increase, which may be because better, cheaper, and more available

Monika Migdalska-Sęk and Karolina H. Czarnecka contributed equally to this work.

Monika Migdalska-Sęk

monika.migdalska-sek@umed.lodz.pl

1 Department of Biomedicine and Genetics, Medical University of Lodz, Pomorska 251 St, 92-213 Lodz, Poland

2 Department of Endocrine, General and Vascular Surgery, Chair of Endocrinology, Medical University of Lodz, Pabianicka 62 St, 93-513 Lodz, Poland diagnostic methods enable the detection of very small changes [1-4]. However, relevant imaging and fine-needle aspiration biopsy (FNAB) are insufficient for diagnosis, and the final diagnosis is established after surgery in up to onequarter of cases. In approximately $30 \%$ of thyroidectomies for suspicion of thyroid cancer in preoperative procedures, the nodular goiter (NG) is confirmed after histopathological verification. The high prevalence of false-positive results leads to "overdiagnosis phenomena" $[2,5]$. On the other hand, the development of diagnostics and the use of thyroid surgery in case of suspicion of cancer mean that patients with differentiated thyroid cancers (DTC) have very good survival rates. After surgery, patients with DTC can receive postoperative radioiodine ablation or thyroid-stimulating hormone (TSH) suppression treatment [6]. However, in a small percentage of patients with DTC, the cancer is more 


\section{Key Points}

The genetic instability of loss of heterozygosity $(\mathrm{LOH})$ and microsatellite instability (MSI) in thyroid tumorigenesis is significant not only in chromosomal region $3 \mathrm{p} 21.3$, where it is important in the early stages, but also in $1 \mathrm{p} 31.2$ and $11 \mathrm{p} 15.5$ regions, where it is highly alternated in advanced stages of thyroid carcinoma.

Analysis of LOH/MSI co-occurrence in several loci, i.e., the overall frequency of allelic loss (OFAL), revealed increased OFAL in follicular adenoma (FA) and follicular thyroid carcinoma (FTC) specimens when compared with nodular goiter (NG) or papillary thyroid carcinoma (PTC), so can be treated as a hallmark of the follicular phenotype and as a promising biomarker to distinguish FA and FTC from NG and PTC.

The observed correlation of OFAL with advanced tumor stage, reflected as larger tumor diameter, higher T stage, and lymph node involvement at diagnosis, suggests OFAL may be considered a putative maker of tumor progression.

aggressive [1, 6]. All this means more interest in molecular markers and molecular methods to support preoperative diagnostics are needed [7].

The classical theory of carcinogenesis, whereby a tumor develops from well-differentiated cells, requires the processes of cell dedifferentiation, uncontrolled proliferation, and loss of apoptotic ability. For thyroid cancer, evidence supports the hypothesis of gradual progression and dedifferentiation of follicular thyroid cells at a genetic level, which clinical epidemiological studies have confirmed [8, 9]. Although several studies have assessed the molecular background of thyroid tumors, understanding of possible molecular mechanisms remains insufficient. It is believed that one of these factors is genetic instability, i.e., loss of heterozygosity (LOH) and microsatellite instability (MSI), as an integral part of thyroid carcinogenesis [10-12]. The frequency of LOH/MSI differs according to cancer subtype and the locus analyzed but is generally higher in follicular thyroid carcinoma (FTC) and slightly lower in papillary thyroid carcinoma (PTC), but in both it is regarded as a mechanism of loss of gene function [11, 13-15]. To date, a high percentage of $\mathrm{LOH}$ has been found in many chromosomal regions (3p12-p21.2, 3p24.2-p25.3, 7q21-q31, 10q22-24, 15q11-q13, 17p13) involving loci of important suppressor genes and oncogenes [14-18]. In our previous study, we observed an increased frequency of elevated LOH/ MSI in PTC mainly at 9p and 16q [19]. Some researchers have proved that the occurrence of LOH/MSI in FTC and PTC can be associated with a more advanced stage of tumor development and invasion [11, 15, 17, 20-22]. However, the clinicopathological significance of LOH/MSI occurrence in thyroid tumors remains to be elucidated. Moreover, the precise mapping of minimally deleted regions in chromosomes is not yet available for thyroid carcinoma. The aim of the present study was to investigate whether LOH/ MSI constitutes an important mechanism in tumorigenesis of lesions derived from thyroid follicular cells and whether genetic alterations in these selected regions may be regarded as important diagnostic and/or prognostic biomarkers in thyroid tumors.

\section{Materials and Methods}

\subsection{Patient Clinical Features and Thyroid Tissue Samples}

This work is based on the analysis of 93 thyroid tissue specimens obtained postoperatively from patients ( $16 \mathrm{men}$, mean age $52 \pm 14.923$ years, and 77 women, mean age $48 \pm 14.132$ years) who underwent total thyroidectomy following an initial diagnosis with FNAB of suspicious for malignancy (Bethesda category V), malignant (Bethesda $\mathrm{VI}$ ), or follicular neoplasm/suspicious for follicular neoplasm (Bethesda IV). We also enrolled patients without a suspected tumor with FNAB (Bethesda II) but who qualified for surgery because of giant NG, retrosternal goiter, airway compression, or thyrotoxic hyperactivity of the NG. Table 1 summarizes the results of cytological verification of FNABs.

The study was a single-center prospective study. The surgeries were performed in the Department of Endocrine, General and Vascular Surgery, Chair of Endocrinology, Medical University of Lodz, Poland, during the years 2011-2016. Thyroid tissue samples (100-150 mg) were obtained from the center of the primary lesion and from matching noncancerous tissue (macroscopically unchanged) from the second lobe. Total tumor tissue samples, immediately after resection, were collected in a stabilization buffer, RNAlater ${ }^{\circledR}$ (Qiagen, Hilden, Germany), homogenized and frozen at $-80{ }^{\circ} \mathrm{C}$ until use. Histopathological diagnoses for thyroid lesions, according to the 7th edition of the American Joint Committee on Cancer (AJCC)/TNM (tumor-node-metastasis) classification system [23], were obtained from pathomorphological reports. No metastasis were detected during surgery for any of the enrolled patients (M0 in pathological TNM [pTNM] classification). Tissues from patients with NG confirmed as benign via histopathology served as references. Table 2 summarizes the results of pathological verification of lesions derived from thyroid follicular cells. 
Table 1 Cytological verification of fine needle aspiration biopsy

\begin{tabular}{|c|c|c|c|c|}
\hline Cytological FNAB verification & Bethesda category & $n$ & $\begin{array}{l}\% \text { of confirmed diagnosis in histo- } \\
\text { pathology }\end{array}$ & $\begin{array}{l}\text { No. of benign } \\
\text { changes in histopa- } \\
\text { thology }\end{array}$ \\
\hline Benign & II & 22 & 54.6 & $12 \mathrm{NG}$ \\
\hline $\begin{array}{l}\text { Follicular neoplasm/suspicious for follicular } \\
\text { neoplasm }\end{array}$ & IV & 36 & 30.5 & $25 \mathrm{NG}$ \\
\hline Suspicious for malignancy & $\mathrm{V}$ & 3 & 100 & None \\
\hline Malignant & VI & 32 & 78.1 & $6 \mathrm{NG}, 1 \mathrm{FA}$ \\
\hline
\end{tabular}

$F N A B$ fine needle aspiration biopsy, $N G$ nodular goiter, $F A$ follicular adenoma

\subsection{Genomic DNA Extraction, Polymerase Chain Reaction, and Loss of Heterozygosity (LOH)/ Microsatellite Instability (MSI) Analysis}

Genomic DNA was extracted from thyroid specimens and the matching macroscopically unchanged thyroid tissue (serving as reference DNA) using QIAamp DNA Mini Kit (Qiagen) according to the manufacturer's protocol. To isolate DNA, the RNA residue was removed using the RNAse A solution (Qiagen). The concentration and quality of the extracted DNA were tested with BioPhotometer ${ }^{\mathrm{TM}}$ plus spectrophotometer (Eppendorf, Hamburg, Germany). DNA samples with a $260 / 280 \mathrm{~nm}$ ratio in the range of 1.8-2.0 were considered high quality and used in further analysis.

Microsatellite analysis was performed using ten microsatellite markers linked to the chromosomal regions $1 \mathrm{p} 31.2$, 3p21.3, 3p24.2, 9p21.3, 11p15.5, and 16q22.1; the cytogenetic location has been described previously [19]. All forward primers were labelled at the $3^{\prime}$ end with a fluorescent dye (6-FAM, NED, PET, or VIC). Table 3 lists the chromosomal locations of the microsatellite markers and nucleotide sequences of primers used in the study.

The amplification reaction of microsatellite markers was performed in a Gradient Mastercycler (Eppendorf) using an AmpliTaq Gold ${ }^{\circledR} 360$ DNA Polymerase Kit (Applied Biosystems, Carlsbad, CA, USA). Reactions were conducted in a total volume of $12.5 \mu \mathrm{l}$ and the reaction mix according to the protocol, as previously reported [19]. In the reaction with every microsatellite marker, the internal controls were used for biological contamination (contamination of foreign DNA, blank samples with nuclease-free water), and for reagent contamination (deionized water instead of AmpliTaq polymerase). The temperatures of the annealing were experimentally set for each pair of primers (Table 3 ).

The amplified products were genotyped by capillary electrophoresis on a 3130xl Genetic Analyzer (Applied Biosystems, Hitachi, NY, USA) and assessed using GeneMapper Software v 4.0 (Applied Biosystems) according to the manufacturer's protocol.
Table 2 Pathological verification of lesions derived from thyroid follicular cell

\begin{tabular}{ll}
\hline Pathological date & $n(\%)$ \\
\hline Histopathological type of the lesion & 93 \\
NG & $43(46)$ \\
FA & $11(12)$ \\
PTC & $31(33)$ \\
FTC & $8(9)$ \\
Minimally invasive & $7(87.5)$ \\
Widely invasive & $1(12.5)$ \\
pTNM & 39 \\
T1a & $16(41)$ \\
T1b & $11(28)$ \\
T2 & $4(10)$ \\
T3 & $8(21)$ \\
Nx & $11(28)$ \\
N0 & $20(51)$ \\
N1 & $8(21)$ \\
M0 & $39(100)$ \\
AJCC & 39 \\
I & $28(72)$ \\
II & $2(5)$ \\
III & $7(18)$ \\
IV & $2(5)$ \\
Primary tumor diameter (mm) & 50 \\
$<10$ & $19(38)$ \\
$10-30$ & $19(38)$ \\
$>30$ & $12(24)$ \\
\hline
\end{tabular}

AJCC American Joint Committee on Cancer, $F A$ follicular adenoma, $F T C$ follicular thyroid carcinoma, $N G$ nodular goiter, $P T C$ papillary thyroid carcinoma, $p T N M$ pathological tumor-node-metastasis

The informativeness of studied samples (heterozygosity) was confirmed when two distinct alleles were detected in the reference sample (DNA from the unchanged thyroid tissue from the same patient). Where only one allele was detected in the reference sample, the sample was classified as noninformative (homozygosity). All further calculations of $\mathrm{LOH} /$ 
Table 3 Characteristics of microsatellite markers used in the study

\begin{tabular}{|c|c|c|c|}
\hline \multirow[t]{2}{*}{ Chromosomal location } & \multicolumn{2}{|c|}{ Nucleotide sequence of the microsatellite marker $\left(5^{\prime}-3^{\prime}\right)$} & \multirow{2}{*}{$\begin{array}{l}\text { Annealing } \\
\text { temperature } \\
\left({ }^{\circ} \mathrm{C}\right)\end{array}$} \\
\hline & Forward & Reverse & \\
\hline \multicolumn{4}{|l|}{$1 \mathrm{p} 31.2$} \\
\hline D1S2137 & ACATCTTTGGTTTGGATAGATG & CAAAACTGCACATTTTGCAC & 55 \\
\hline D1S368 & GGGCATTGTTTAGGGGTG & TAGTGGGCTTTACGTCTGC & 53 \\
\hline \multicolumn{4}{|l|}{$3 \mathrm{p} 21.3$} \\
\hline D3S3615 & CCAGGGTCTGTGTGAATGTG & CCCACAGGAGGCATTCAG & 47 \\
\hline \multicolumn{4}{|l|}{$3 \mathrm{p} 24.2$} \\
\hline D3S1583 & AGCTTGTAAATAGGTCCTAACAGAG & TGGTTTAATAGGCACCGTTT & 58 \\
\hline \multicolumn{4}{|l|}{$9 \mathrm{p} 21.3$} \\
\hline D9S974 & GAGCCTGGTCTGGATCATAA & AAGCTTACAGAACCAGACAG & 55.5 \\
\hline D9S1604 & CCTGGGTCTCCAATTTGTCA & AGCACATGACACTGTGTGTG & 55.5 \\
\hline \multicolumn{4}{|l|}{$11 \mathrm{p} 15.5$} \\
\hline D11S4088 & GGGCAGAGGCAGTGGAG & GCATGTTTCGGGGGTG & 55.5 \\
\hline D11S1318 & CCCGTATGGCAACAGG & TGTGCATGTNCATGAGTG & 47 \\
\hline \multicolumn{4}{|l|}{$16 \mathrm{q} 22.1$} \\
\hline D16S496 & GAAAGGCTACTTCATAGATGGCAAT & ATAAGCCACTGCGCCCAT & 54 \\
\hline D16S3025 & TCCATTGGACTTATAACCATG & AGCTGAGAGACATCTGGG & 45 \\
\hline
\end{tabular}

MSI frequency involved only informative cases. LOH/MSI was evaluated by calculating the ratio of the fluorescence intensity of the alleles originating from an unchanged thyroid tissue sample (N, normal, i.e., control sample) to the fluorescence intensity of the alleles originating from noncancerous or cancerous lesions (T). For each informative DNA pair (paired $\mathrm{T}$ and $\mathrm{N}$ samples), an allelic imbalance ratio was calculated based on the maximum allele peak heights (fluorescence intensity), as follows: $\mathrm{N}$-allele 1: $\mathrm{N}$-allele 2/T-allele 1: T-allele 2 (N1:N2/T1:T2) according to the protocol [19]. $\mathrm{LOH}$ in samples was considered indicative when the allelic imbalance ratio was $<0.67$ or $>1.35$ (according to the criteria of the GeneMapper software v. 4.0). MSI was considered indicative if one or more additional alleles were present in the $\mathrm{T}$ sample as compared with the $\mathrm{N}$ sample.

LOH/MSI frequency was calculated as a percentage of $\mathrm{LOH} / \mathrm{MSI}$ alteration presence in relation to all informative loci (heterozygous DNA). For each studied sample, the fractional allele loss (FAL) value was also calculated. FAL describes the ratio of the total number of chromosomal loci with LOH/MSI to the total number of informative loci in all examined ten microsatellite loci. Overall frequency of allelic loss (OFAL) - a percentage of LOH/MSI coincidences in all microsatellite markers-was assessed.

\subsection{Statistical Analysis}

We used the Chi squared test $\left(\chi^{2}\right)$ to assess the frequency of LOH/MSI among different markers or chromosomal regions, correlation between incidence of LOH/MSI in a particular chromosomal region with studied clinical parameters (patient characteristics: age, sex and tumor staging according to the pTNM and AJCC classifications, histopathological group, and primary tumor diameter [Td]). For small groups, we used Fisher's exact test, and this test was also applied to compare the frequency of LOH/MSI in the studied chromosomal regions depending on the sex of the patient. Nonparametric (Kruskal-Wallis and Mann-Whitney $U$ tests) were used to assess the possible relationship between OFAL and examined clinicopathological parameters. The statistical evaluation of differences between multiple groups was carried out using the post hoc Newman-Keuls test. The results are presented as mean \pm standard error of the mean and mean \pm standard deviation. In all tests, the accepted level of statistical significance was estimated at $P<0.05$. Statistica ${ }^{\circledR}$ for Windows 10.0 (StatSoft, Cracow, Poland) was used for statistical analysis.

\subsection{Ethics Statement}

The study was approved by the Bioethical Committee of the Medical University of Lodz, Poland (Resolution no. RNN/217/11/KE). All participants signed an individual consent form.

\section{Results}

In total, 93 DNA specimens (DNA from the noncancerous or cancerous lesion tissue paired with its matching DNA from the macroscopically unchanged tissue) underwent LOH/ MSI analysis using a panel of ten microsatellite markers. 
All studied DNA samples were informative for at least two studied markers. The informativity of the markers was in the range of $51.61-88.17 \%$ (mean $70.86 \pm 13.45$ ) and are summarized in Table 4. LOH/MSI changes were observed for all $(100 \%)$ microsatellite markers and in 27 of 93 patients $(29 \%)$.

\subsection{LOH/MSI Frequency for Individual Microsatellite Markers and Chromosomal Regions}

The LOH/MSI frequency (\%) was evaluated separately for each marker used in the study. The highest frequency of LOH/MSI (12.28\%) was observed for the D3S3615 marker, spanning the chromosomal region $3 \mathrm{p} 21.3$, followed by the D1S368 marker $(11.11 \%)$ covering the chromosomal region 1p31.2. (Table 4).

Focusing on a comparison of LOH/MSI frequencies between the studied chromosomal regions, the highest LOH/MSI frequency was observed for $11 \mathrm{p} 15.5$ (14.29\%). The LOH/MSI frequencies in 1p31.2, 3p21.3, and 9p21.3 were similar and assessed as $12 \%$. The lowest LOH/MSI frequency $(10 \%)$ was observed in the 3 p24.2 and $16 \mathrm{q} 22.1$ regions.

Statistical analysis did not confirm a significant difference in LOH/MSI frequency between particular markers or between studied chromosomal regions $\left(P>0.05 ; \chi^{2}\right.$ test, data not shown).

\subsection{LOH/MSI Frequency in Correlation with Clinicopathological Parameters}

The presence of LOH/MSI in samples was used in calculation of (1) LOH/MSI frequency in a particular chromosomal region (regional LOH/MSI score), (2) FAL index evaluation

Table 4 Informative rate and loss of heterozygosity/microsatellite instability-positive cases for each microsatellite marker

\begin{tabular}{|c|c|c|c|c|c|}
\hline \multirow[t]{2}{*}{$\begin{array}{l}\text { Chromosomal } \\
\text { location }\end{array}$} & \multirow[t]{2}{*}{ Marker } & \multicolumn{2}{|c|}{ Informative cases } & \multicolumn{2}{|c|}{$\begin{array}{l}\text { LOH/MSI- } \\
\text { positive cases }\end{array}$} \\
\hline & & $n$ & $\%$ total & $N$ & $\%$ \\
\hline \multirow[t]{2}{*}{$1 \mathrm{p} 31.2$} & D1S2137 & 79 & 84.95 & 3 & 3.80 \\
\hline & D1S368 & 63 & 67.74 & 7 & 11.11 \\
\hline \multirow[t]{2}{*}{$3 p 21.3$} & D3S3615 & 57 & 61.29 & 7 & 12.28 \\
\hline & D3S1583 & 48 & 51.61 & 5 & 10.42 \\
\hline \multirow[t]{2}{*}{$9 \mathrm{p} 21.3$} & D9S974 & 75 & 80.65 & 5 & 6.67 \\
\hline & D9S1604 & 53 & 56.99 & 5 & 9.43 \\
\hline \multirow[t]{2}{*}{$11 \mathrm{p} 15.5$} & D11S4088 & 82 & 88.17 & 6 & 7.32 \\
\hline & D11S1318 & 80 & 86.02 & 7 & 8.75 \\
\hline \multirow[t]{2}{*}{$16 \mathrm{q} 22.1$} & D16S496 & 67 & 72.04 & 6 & 8.96 \\
\hline & D16S3025 & 55 & 59.14 & 3 & 5.45 \\
\hline
\end{tabular}

LOH loss of heterozygosity, MSI microsatellite instability for a particular sample, (3) OFAL-a percentage of $\mathrm{LOH} /$ MSI coincidences in all microsatellite markers and analyzed separately for variants (1-3) in relation to patients' clinical features (sex, age at diagnosis) and the histopathological characteristics of tumors (according to the TNM and AJCC classifications), histopathological types, and primary $\mathrm{Td}$.

\subsubsection{Regional LOH/MSI Score vs. Clinicopathological Parameters}

LOH/MSI incidence was higher in men than in women in all analyzed regions (1p31.2, 3p21.3, 3p24.2, 7q32.2, 9p21.3, $11 \mathrm{p} 15.5$, and $16 \mathrm{q} 22.1)$ but this was not statistically significant $(P>0.05$; Fisher's exact test, data not shown). Among men, the observed LOH/MSI incidence in $11 \mathrm{p} 15.5(43.75 \%)$ was significantly higher than in other regions $(P=0.021$; $\chi^{2}$ test)

The comparison of LOH/MSI frequency between the studied chromosomal regions in all histopathological types of lesions derived from thyroid follicular cells (NG, FA, FTC, PTC) revealed regions with significantly increased LOH/MSI frequencies for specific histotypes: the 3p24.2 region for FA $\left(P=0.001 ; \chi^{2}\right.$ test $)$ and $1 \mathrm{p} 31.2$ for FTC $\left(P=0.017 ; \chi^{2}\right.$ test $)$. LOH/MSI in 3 p21.3 was significantly elevated in malignant lesions derived from PTC and FTC ( $P=0.001$ and $P=0.001$, respectively; $\chi^{2}$ test).

When analyzed using TNM classification, a significantly increased frequency of LOH/MSI was observed in the $3 \mathrm{p} 21.3$ locus for the T1a $+\mathrm{T} 1 \mathrm{~b}$ group $\left(P=0.001 ; \chi^{2}\right.$ test) and in the $1 \mathrm{p} 31.2$ and $11 \mathrm{p} 15.5$ regions for the T2-T3 group ( $P=0.001$ and $P=0.003$, respectively; $\chi^{2}$ test). Using degree of lymph node involvement (the ' $N$ ' value), $\mathrm{LOH} /$ MSI frequency was analyzed in $\mathrm{N} 0+\mathrm{Nx}$ versus $\mathrm{N} 1$ groups. We combined the $\mathrm{N} 0$ and $\mathrm{Nx}$ groups, because according to the AJCC staging, stage I accounted for both cases with pT1N0M0 and those with pT1NxM0. We observed a significantly increased frequency of LOH/MSI in the $3 \mathrm{p} 21.3$ locus for the $\mathrm{N} 0+\mathrm{Nx}$ group $\left(P=0.001 ; \chi^{2}\right.$ test $)$ and in the $1 \mathrm{p} 31.2$ and $11 \mathrm{p} 15.5$ regions for the $\mathrm{N} 1$ group $(P=0.001$ and $P=0.003$, respectively; $\chi^{2}$ test .

In relation to AJCC classification, the highest incidence of allelic imbalance for the AJCC I group was noted in the 3p21.3 locus, and the differences were statistically significant $\left(P=0.005 ; \chi^{2}\right.$ test $)$. Analysis revealed a statistically significant increase in LOH/MSI frequency for the AJCC II-IV group in the $1 \mathrm{p} 31.2$ and $11 \mathrm{p} 15.5$ regions $(P=0.002$ and $P=0.040$, respectively; $\chi^{2}$ test).

In reference to primary $\mathrm{Td}$, a significantly higher frequency of allelic imbalance was observed in 3 p21.3 for the group with thyroid $\mathrm{Td}<10 \mathrm{~mm}\left(P=0.001 ; \chi^{2}\right.$ test $), 1 \mathrm{p} 31.2$ for Td $10-30 \mathrm{~mm}\left(P=0.004 ; \chi^{2}\right.$ test $)$, and in $11 \mathrm{p} 15.5$ for $\mathrm{Td}>30 \mathrm{~mm}\left(P=0.004 ; \chi^{2}\right.$ test $)$. 
Table 5 Loss of heterozygosity/microsatellite instability frequency (\%) in studied chromosomal regions within individual pathological groups

\begin{tabular}{|c|c|c|c|c|c|c|}
\hline \multirow[t]{2}{*}{ Pathological features } & \multicolumn{6}{|c|}{ LOH/MSI frequency $(\%)$ in chromosomal region } \\
\hline & $1 \mathrm{p} 31.2$ & $3 p 21.3$ & $3 \mathrm{p} 24.2$ & $9 \mathrm{p} 21.3$ & $11 \mathrm{p} 15.5$ & $16 \mathrm{q} 22.1$ \\
\hline \multicolumn{7}{|l|}{ Histopathological type } \\
\hline NG & 7 & 7 & 14 & 17 & 17 & 13 \\
\hline FA & 20 & 11 & $40^{\mathrm{a}}$ & 25 & 20 & 20 \\
\hline PTC & 11 & $16^{\mathrm{a}}$ & 0 & 0 & 6 & 7 \\
\hline FTC & $29^{\mathrm{a}}$ & $33^{\mathrm{a}}$ & 0 & 25 & 25 & 0 \\
\hline \multicolumn{7}{|l|}{ pTNM } \\
\hline $\mathrm{T} 1 \mathrm{a}+\mathrm{T} 1 \mathrm{~b}$ & 4 & $20^{\mathrm{a}}$ & 0 & 0 & 0 & 4 \\
\hline $\mathrm{T} 2-\mathrm{T} 3$ & $44^{\mathrm{a}}$ & 14 & 0 & 18 & $33^{\mathrm{a}}$ & 9 \\
\hline $\mathrm{N} 0+\mathrm{Nx}$ & 7 & $18^{\mathrm{a}}$ & 0 & 8 & 6 & 4 \\
\hline N1 & $38^{\mathrm{a}}$ & 20 & 0 & 0 & $25^{\mathrm{a}}$ & 13 \\
\hline \multicolumn{7}{|l|}{ AJCC } \\
\hline I & 12 & $20^{\mathrm{a}}$ & 0 & 4 & 7 & 8 \\
\hline II-IV & $22^{\mathrm{a}}$ & 14 & 0 & 11 & $18^{\mathrm{a}}$ & 0 \\
\hline \multicolumn{7}{|l|}{$\mathrm{Td}(\mathrm{mm})$} \\
\hline$<10$ & 6 & $20^{\mathrm{a}}$ & 0 & 11 & 0 & 0 \\
\hline $10-30$ & $25^{\mathrm{a}}$ & 15 & 0 & 6 & 11 & 11 \\
\hline$>30$ & 18 & 13 & 25 & 10 & $33^{\mathrm{a}}$ & 22 \\
\hline
\end{tabular}

AJCC American Joint Committee on Cancer stage, FA follicular adenoma, FTC follicular thyroid carcinoma, LOH loss of heterozygosity, MSI microsatellite instability, $N O / N x$ no regional lymph node involvement, $N 1$ regional lymph node involvement, $N G$ nodular goiter, $P T C$ papillary thyroid carcinoma, $p T N M$ pathological tumor-node-metastasis, $T 1$ tumor size pT1, T2-T3 tumor size pT2-T3, $T d$ tumor diameter

${ }^{a}$ Comparison between particular chromosomal regions within an individual pathological group $P<0.05$

Table 5 summarizes the findings for LOH/MSI frequency in particular chromosomal regions within an individual pathological group.

\subsubsection{Fractional Allelic Loss (FAL) Index vs. Clinicopathological Parameters}

FAL indices were evaluated only for thyroid samples for which LOH/MSI was present in at least one microsatellite locus. The highest FAL value was 0.75 (Table 6). The FAL mean value was $0.224 \pm 0.266$ in men and $0.0488 \pm 0.107$ in women. Table 6 depicts the results of LOH/MSI frequency in at least one locus in relation to sex.

Statistical analysis showed significant differences in FAL levels between sex cohorts $(P=0.015$, Mann-Whitney $U$ test), with significantly higher FAL values in men. There were no statistically significant correlations between the FAL index value and patient age, histotype, and other clinicopathological parameters (pTNM, AJCC, Td; $P>0.05$; data not shown).

Mean FAL was evaluated regarding FNAB cytological verification. Patients were grouped according to Bethesda classification: II, IV, and V + VI. As only three patients were classified as Bethesda $\mathrm{V}$ (suspicious for malignancy), these patients were combined with the Bethesda VI (malignant) group for analysis. No statistically significant differences were observed ( $P=0.402$, Kruskal-Wallis test; data not shown) Afterwards, in each FNAB group (II, IV, V + VI), analysis comparing mean FAL values between valid (confirmed by histopathology) and incorrect FNAB diagnoses was performed. No statistically significant differences were found ( $P>0.05$, Mann-Whitney $U$ test; data not shown).

\subsubsection{Overall Frequency of Allelic Loss (OFAL) vs. Clinicopathological Parameters}

OFAL occurred significantly more often in men than in women (mean 22.66 vs. $5.21 \%$; $P=0.002$; Mann-Whitney $U$ test)

Patients were divided into the following groups according to age at time of diagnosis: (1) $\leq 40$ years, (2) 40-60 years, (3) $>60$ years. Significant differences were found between them ( $P=0.038$; Kruskal-Wallis test) (Fig. 1).

Statistically significantly increased OFAL was revealed in patients aged $<40$ years as compared with patients aged $>60$ years (mean 10.52 vs. $4.32 \% ; P=0.016$; Newman-Keuls test).

Concerning histopathological characteristics of the lesion (NG, FA, FTC, PTC), we revealed significant differences in OFAL values between the histotypes $(P=0.033$, Kruskal-Wallis test). The average OFAL was highest in the FA group (mean 17.73\%) and was significantly higher 
Table 6 The assessed loss of heterozygosity/microsatellite instability frequency (fractional allelic loss index) in groups by sex

\begin{tabular}{|c|c|c|c|c|c|c|c|c|c|c|c|}
\hline Sample & D1S2137 & D1S368 & D3S3615 & D3S1583 & D9S974 & D9S1604 & D11S4088 & D11S1318 & D16S496 & D16S3025 & FAL \\
\hline \multicolumn{12}{|l|}{ Women } \\
\hline W1 & I & I & NI & I & $\mathrm{LOH}$ & I & I & I & I & I & 0.11 \\
\hline W2 & I & I & MSI & NI & I & NI & I & I & I & I & 0.13 \\
\hline W3 & I & NI & NI & I & $\mathrm{LOH}$ & $\mathrm{LOH}$ & I & I & I & I & 0.25 \\
\hline W4 & I & I & I & I & I & I & I & NI & $\mathrm{LOH}$ & I & 0.11 \\
\hline W5 & I & I & I & $\mathrm{LOH}$ & I & I & NI & NI & I & I & 0.13 \\
\hline W6 & I & I & I & I & $\mathrm{LOH}$ & NI & I & I & I & NI & 0.13 \\
\hline W7 & I & $\mathrm{LOH}$ & NI & NI & I & I & I & I & I & NI & 0.14 \\
\hline W8 & $\mathrm{LOH}$ & NI & I & NI & I & I & I & $\mathrm{LOH}$ & I & NI & 0.29 \\
\hline W9 & NI & NI & $\mathrm{LOH}$ & NI & I & $\mathrm{LOH}$ & I & I & I & I & 0.29 \\
\hline W10 & I & NI & NI & I & I & NI & I & $\mathrm{LOH}$ & I & I & 0.14 \\
\hline W11 & I & I & I & NI & I & I & $\mathrm{LOH}$ & $\mathrm{LOH}$ & I & NI & 0.25 \\
\hline W12 & I & I & $\mathrm{LOH}$ & I & I & I & NI & I & I & NI & 0.13 \\
\hline W13 & I & $\mathrm{LOH}$ & I & NI & I & NI & I & I & I & NI & 0.14 \\
\hline W14 & I & I & NI & $\mathrm{LOH}$ & I & $\mathrm{LOH}$ & I & I & I & NI & 0.25 \\
\hline W15 & NI & NI & $\mathrm{LOH}$ & I & I & $\mathrm{LOH}$ & I & I & I & I & 0.25 \\
\hline W16 & MSI & I & NI & NI & I & I & I & I & NI & I & 0.14 \\
\hline W17 & NI & NI & NI & NI & NI & I & I & I & $\mathrm{LOH}$ & NI & 0.25 \\
\hline W18 & MSI & $\mathrm{LOH}$ & I & NI & I & I & $\mathrm{LOH}$ & MSI & $\mathrm{LOH}$ & NI & 0.63 \\
\hline \multicolumn{12}{|l|}{ Men } \\
\hline M1 & I & $\mathrm{NI}$ & NI & NI & NI & NI & NI & I & $\mathrm{LOH}$ & $\mathrm{LOH}$ & 0.50 \\
\hline M2 & I & $\mathrm{LOH}$ & I & I & NI & NI & I & I & I & I & 0.13 \\
\hline M3 & NI & I & I & NI & I & I & $\mathrm{LOH}$ & $\mathrm{LOH}$ & I & I & 0.25 \\
\hline M4 & I & I & $\mathrm{LOH}$ & I & I & I & I & I & I & NI & 0.11 \\
\hline M5 & I & $\mathrm{LOH}$ & NI & I & I & NI & $\mathrm{LOH}$ & $\mathrm{LOH}$ & NI & NI & 0.50 \\
\hline M6 & I & I & I & $\mathrm{LOH}$ & NI & I & I & $\mathrm{LOH}$ & NI & I & 0.25 \\
\hline M7 & I & $\mathrm{LOH}$ & $\mathrm{LOH}$ & $\mathrm{LOH}$ & NI & NI & $\mathrm{LOH}$ & I & $\mathrm{LOH}$ & $\mathrm{LOH}$ & 0.75 \\
\hline M8 & I & NI & NI & NI & $\mathrm{LOH}$ & NI & I & NI & I & $\mathrm{LOH}$ & 0.40 \\
\hline M9 & I & $\mathrm{LOH}$ & $\mathrm{LOH}$ & $\mathrm{LOH}$ & $\mathrm{LOH}$ & $\mathrm{LOH}$ & $\mathrm{LOH}$ & I & $\mathrm{LOH}$ & I & 0.70 \\
\hline
\end{tabular}

FAL fractional allelic loss, I informative loci without LOH/MSI (heterozygote), $L O H$ loss of heterozygosity, $M$ men, $M S I$ presence of microsatellite instability, NI non-informative allelotype (homozygote), $W$ women

than in the NG and PTC groups (mean $8.82 \%, P=0.049$; mean $4.06 \%, P=0.006$, respectively; Mann-Whitney $U$ test; Fig. 2a). Differences in OFAL values between NG and PTC were also statistically significant $(P=0.026$, Mann-Whitney $U$ test). In addition, comparison of OFAL values between follicular lesions (FA and FTC together) versus PTC versus NG demonstrated significantly higher OFAL values in follicular neoplasms ( $P=0.008$, Kruskal-Wallis test), and Mann-Whitney $U$ test confirmed the differences between the follicular and papillary changes (mean 14.40 vs. $4.06 \%$, $P=0.009$ ).

Statistically significant differences in OFAL values were observed for tumor size and regional lymph node involvement according to pTNM classification. OFAL was significantly higher in the $\mathrm{T} 1 \mathrm{a}+\mathrm{T} 1 \mathrm{~b}$ than in the $\mathrm{T} 2-\mathrm{T} 3$ groups (mean 2.95 vs. $15.69 \%$, respectively; Mann-Whitney $U$ test, $P=0.021$; Fig. 2b). According to the presence of lymph node involvement (the ' $N$ ' value), OFAL values were higher in the $\mathrm{N} 1$ than in the $\mathrm{N} 0+\mathrm{Nx}$ group (mean 10.69 vs. $4.75 \%$ ), but this was not statistically significant $(P=0.373$, Mann-Whitney $U$ test). No significant correlations were found between OFAL values and tumor staging according to AJCC classification ( $P=0.104$, Mann-Whitney $U$ test; data not shown).

Statistically significant differences in OFAL values were observed in terms of primary $\mathrm{Td}(<10 \mathrm{~mm}$, $10-30 \mathrm{~mm},>30 \mathrm{~mm})(P=0.044$; Kruskal-Wallis test $)$. The Newman-Keuls multiple comparison test revealed statistically significant differences between thyroid tumors sized $<10 \mathrm{~mm}$ versus $>30 \mathrm{~mm}$ ( 4.10 vs. $13.97 \% ; P=0.027$; Fig. 2c).

OFAL was also evaluated in groups according to FNAB cytological verification (Bethesda II vs. IV vs. V+ VI). The highest OFAL was observed in the benign group (Bethesda II; mean $11.58 \%$ ), whereas values were similar between the 


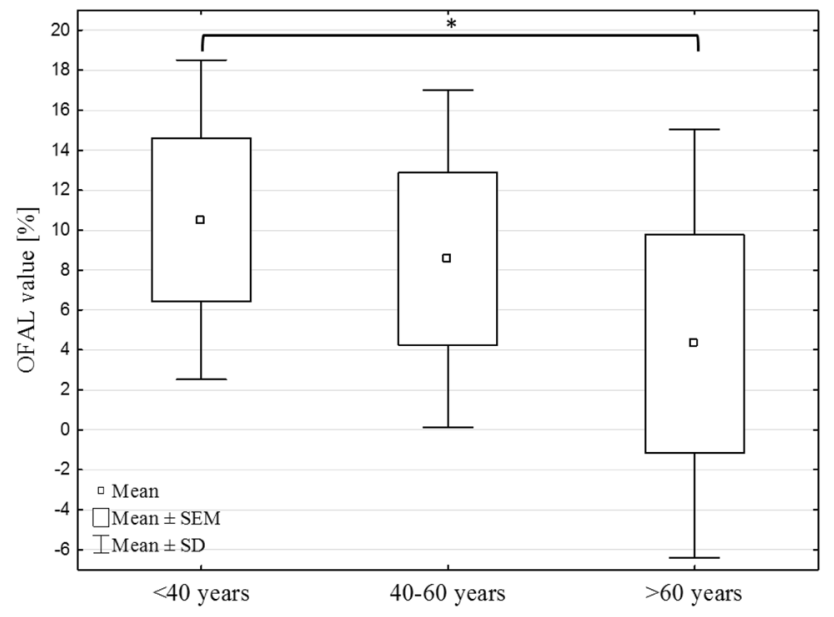

Fig. 1 Box-and-whisker plot representing mean overall frequency of allelic loss values in the studied age groups. ${ }^{*} P<0.05$. OFAL overall frequency of allelic loss, $S E M$ standard error of the mean, $S D$ standard deviation

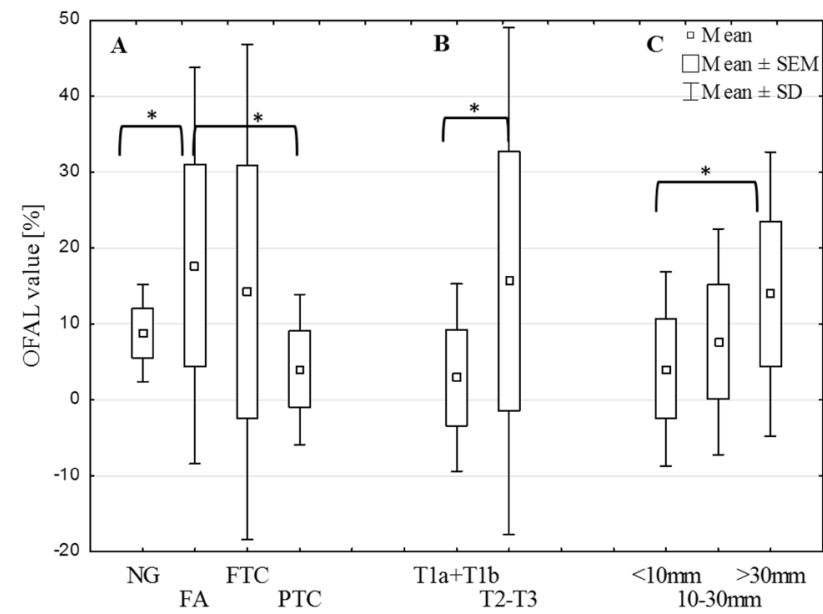

Fig. 2 Box-and-whisker plots showing mean overall frequency of allelic loss in the studied groups, according to a histopathological types, $\mathbf{b}$ tumor size (pTNM classification), $\mathbf{c}$ primary tumor diameter; $* P<0.05$. FA follicular adenoma, FTC follicular thyroid carcinoma, $N G$ nodular goiter, OFAL overall frequency of allelic loss, $P T C$ papillary thyroid carcinoma, $T 1 a+T 1 b$ tumor size pT1a-1b, T2-3 tumor size pT2-3, $S D$ standard deviation, SEM standard error of the mean

IV and V/VI groups (mean 7.14 and $7.40 \%$, respectively). Differences were not statistically significant $(P=0.196$, Kruskal-Wallis test). The next analysis compared OFAL values in FNAB diagnosis groups (II, IV, V + VI) between valid (confirmed by histopathology) and incorrect FNAB diagnoses. The OFAL value was significantly elevated in the incorrect diagnosis group: entire group (mean OFAL 11.325 vs. $5.718, P=0.010024$; Mann-Whitney $U$ test), Bethesda II group (mean OFAL 18.147 vs. $4.79, P=0.0163$;
Mann-Whitney $U$ test), and Bethesda V + VI group (mean OFAL 14.359 vs. $5.892, P=0.0164$; Mann-Whitney $U$ test).

\section{Discussion}

We performed comprehensive allelotyping in the following chromosomal regions: $1 \mathrm{p} 31.2,3 \mathrm{p} 21.3-24.2,9 \mathrm{p} 21.3$, $11 \mathrm{p} 15.5$, and $16 \mathrm{q} 22.1$. Considering the paucity of previously published studies on LOH/MSI frequency in $1 \mathrm{p}, 9 \mathrm{p}$, $11 \mathrm{p}$, and $16 \mathrm{q}$ in thyroid cancer, our study seems interesting and valuable [10, 15, 18, 19, 22, 24, 25]. We focused on many markers covering loci of genes important in carcinogenesis and located on different chromosomes. Our results provided evidence for the presence of LOH/MSI alterations in all studied thyroid lesion samples, with the highest incidence in $11 \mathrm{p} 15.5$, followed by $1 \mathrm{p} 31.2,3 \mathrm{p} 21.3$, and $9 \mathrm{p} 21.3$.

As yet, neither the molecular effects of events in the thyroid gland nor the link with predictors of tumor outcome or therapeutic potential for patients has been fully determined. In view of a large number of thyroid cancer misdiagnoses in preoperative biopsies, "overdiagnosis phenomena", resulting in unnecessary surgery and a group of DTC patients with more aggressive outcomes, we aimed to search for thyroid cancer diagnostic/prognostic markers $[1,2,5,6]$. The results of our study correlated with clinical and histopathological features of thyroid tumors, revealing significant associations with LOH/MSI frequency in individual chromosomal regions (Fig. 3). As we discuss in the following paragraphs, these regions contain loci of specific genes whose silencing through LOH/MSI may result in the development/progression of thyroid cancer.

The results of our study confirm the involvement of $\mathrm{LOH} / \mathrm{MSI}$ in the $1 \mathrm{p} 31.2$ region in the progression from FA to FTC, the frequency of which increased from 20 to $29 \%$, respectively. Other researchers have similarly found genetic alterations in 1p31, especially in FA (10-22\%) and in FTC (57-69\%) [18, 26]. Additionally, the involvement of $\mathrm{LOH} / \mathrm{MSI}$ in $1 \mathrm{p} 31.2$ in thyroid cancer progression is further emphasized by its significantly increased frequency in patients with more advanced stage/grade cancer development and greater Td. Previous work found that neighboring subregions, i.e., $1 \mathrm{p} 32$ and $1 \mathrm{p} 35-36$, were associated with aggressive course, tumor progression, and development of a bigger lesion in advanced stages of thyroid cancer [22, 24].

Such results strongly support the significance of genes located in $1 \mathrm{p} 31$ in thyroid carcinogenesis. An example of such genes is the tumor-suppressor gene (TSG) ARHI, which inhibits cell growth, motility, and invasion. Expression of $A R H I$ was decreased in breast, ovarian, pancreatic, and esophageal carcinogenesis, and its silencing was also observed in follicular thyroid neoplasia [19, 26-28]. 


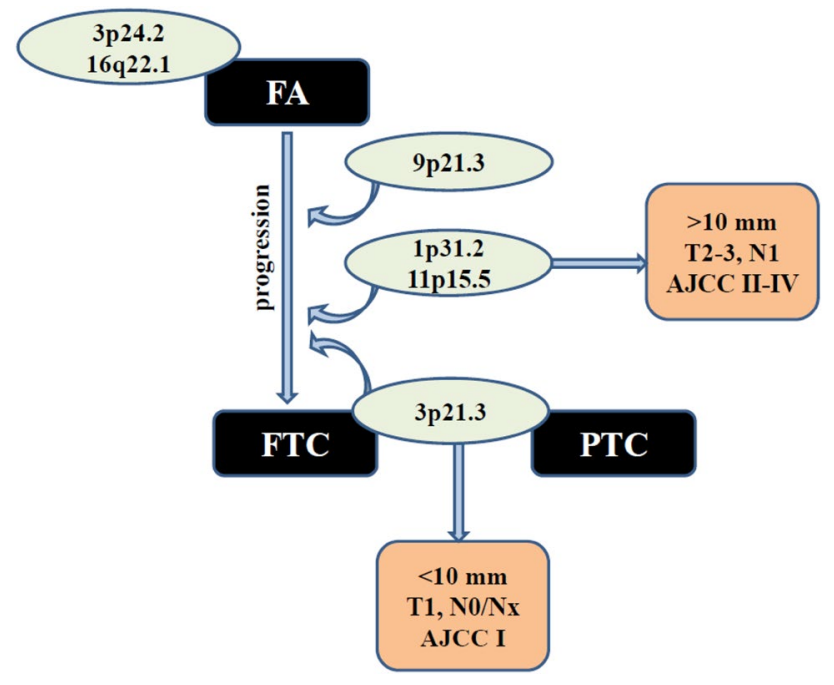

Fig. 3 Diagram showing LOH/MSI "hot spot" of chromosomal regions identified in analyzed histotypes of the thyroid lesions. We emphasize the regions identified in our study that may play a key role in transformation of the follicular cell toward FTC: 1p31.2, 9p21.3, 11p15.5 and the 3p21.3 region, also important in PTC. LOH in 3p24.2 and 16q22.1 appears to have a protective role, since loss has been found in FA but not in FTC, meaning that somehow it may block the progression of FA to FTC. Considering the tumor characteristics (TNM, AJCC, Td), we also highlight regions in which we obtained statistically significant high frequencies of LOH/MSI within an individual pathological group (according to Table 5). AJCC I American Joint Committee on Cancer stage I, AJCC II-IV American Joint Committee on Cancer stage II-IV, FA follicular adenoma, FTC follicular thyroid carcinoma, $\mathrm{LOH}$ loss of heterozygosity, MSI microsatellite instability, $N O / N x$ no regional lymph node involvement, $N 1$ regional lymph node involvement, $P T C$ papillary thyroid carcinoma, $T 1$ tumor size pT1, T2-T3 tumor size pT2-T3

Similar to $1 \mathrm{p} 31.2$, the highest LOH/MSI frequency in $11 \mathrm{p} 15.5$ was shown for FA (20\%) and FTC (25\%). These results are in accordance with those of Sarquis et al. [18], who observed an even higher LOH frequency (42\%) in both FAs and FTCs. Genetic alterations in 11p15.5 can be linked with the inactivation of TSGs located in this region. The markers used in our study cover the imprinted domain of the so-called $K C N Q 1$ cluster, which, along with the $K C N Q 1$ gene, also involves SLC22A18, CDKN1C, TSSC4, CD81, and $P H L D A 2$, most of which have proven suppressive roles [29]. It is assumed that, in the case of parental imprinting, the silencing of the active copy of the gene through one of a number of possible genetic events (including LOH) may cause excessive cell proliferation [18]. Among others, lack of KCNQ1 protein was proven to interfere with the regulation of cell proliferation in the thyroid gland [30]. Our study confirmed an association between genetic instability in the KCNQ1 locus and more advanced thyroid carcinoma (clinical stage T2-3, N1, AJCC II-IV) and greater Td (> $30 \mathrm{~mm})$. Elevated LOH/MSI in this region, especially in FA and FTC, seems to lead to malignant progression.
Similarly, in 9p21.3, a high frequency was observed in both the FA and the FTC groups, and genes located in this region also account for parental imprinting. The frequency of LOH/MSI in 9p21.3 observed in other studies was lower in FA (6\%) but varied in FTC $(11-44 \%)[15,31]$. One of the most important genes in $9 \mathrm{p} 21.3$ is $C D K N 2 A / B$, whose implications in cell cycle regulation and participation in the late stage of carcinogenesis has been clearly documented $[32,33]$. In our study, genetic alterations in 9 p21.3 were more frequently observed in advanced thyroid tumors. In our previous study, LOH/MSI in the locus of this gene was the highest among other analyzed loci (ARHI, KNCQ1,CDHI) [19].

In the 3p21.3 region, we documented for the first time a statistically significant increase in LOH/MSI frequency in malignant lesions for FTC (33\%) and PTC (16\%) compared with for FA and NG. Other researchers have observed LOH on a comparable level in both FTC and PTC (22\% and 10\%, respectively), although they analyzed the neighboring region 3p21.2-p14.2. In their study, two minimal common deletion regions were defined for FTC (mapped to $3 \mathrm{p} 25.3 \sim$ pter and 3p21.2 p12) and one for PTC (3p25.3-24.2) [14]. Genetic instability in this chromosomal region is also specific in other cancers such as lung, breast, or kidney, where numerous TSGs were recognized within the two so-called frequently affected regions in 3p21.3 [34]. One of these genes is RASSF1A, which encodes protein taking part in apoptotic processes, the stabilization of cytoplasmic microtubules, and cell cycle progression $[35,36]$. In vitro analysis of RASSF $1 A$ function revealed its suppressor activity in cells, i.e., blocking tumor growth in many cancers (lung, breast, ovarian, and renal) [37, 38].

Remarkably, in our study, genetic instability in the 3 p21.3 region was significantly higher in smaller and lower-grade tumors. It was also observed in FA and NG, albeit without statistical significance. Such results support the findings that the incidence of LOH/MSI in 3p21.3 is increased in early clinical stages of thyroid tumor. Indeed, molecular changes in RASSF1A locus leading to gene silencing (promoter hypermethylation) were observed in FA and NG and also in the macroscopically unchanged thyroid tissue surrounding PTC [19, 39-41].

Unlike $3 p 21.3$, we did not detect any genetic alterations in the neighboring chromosomal region 3p24.2 in FTC and PTC samples, but we did find them in FA (40\%) and NG (14\%). The results of other studies are similar in relation to FA (14-27\%), but genetic alterations in this region were also found in FTC (10-27\%) and PTC (46\%) [14, 42]. Still, such results allow the inclusion of $3 \mathrm{p} 24.2$ as the "hot" initiation site of the carcinogenesis or transformation into a benign lesion characteristic of premalignant thyroid lesions. A high percentage of LOH/MSI in 3p24.2 in FA may indicate the protective role of this region in progression of follicular cells 
toward FTC, which can be associated with inactivation of genes taking part in cancer initiation, but is not crucial in the progression process. $R A R B$ is one of the genes within this locus, encoding the beta-retinoic acid receptor, playing an important role in growth regulation, differentiation, and apoptosis. Its expression was downregulated in thyroid carcinoma $[42,43]$. The mechanisms responsible for expression silencing have not yet been fully elucidated, but a high level of LOH occurrence (44\% of thyroid carcinomas and $27 \%$ of FA) in RARB locus was demonstrated [42]. Our studies appear to confirm that the LOH/MSI in RARB locus may be one of the first molecular events, albeit not enough for further tumor progression. According to one of the most recent studies, this phenomenon can be explained via the suppressive action of microRNA (miRNA). Inhibition of miRNA-146a and miRNA-146b families results in restoration of $R A R B$ expression and decreased thyroid cancer cell proliferation rates [43].

For the chromosomal region 16q22.1, we used two markers that flanked the $C D H 1$ and $C D H 3$ genes proximally and distally. Inactivation of those TSGs may implicate uncontrolled proliferation, leading to a malignant phenotype [44]. In our study, we observed an increasing LOH/MSI frequency along with increasing $\mathrm{Td}$ in cancer samples, which confirms the findings of Kim et al. [15]. However, its frequency in malignant thyroid tumors was low $(<7 \%)$ and much higher in NG and FA lesions (13-20\%). These findings indicate a role for $C D H 1 / 3$ silencing via $\mathrm{LOH} / \mathrm{MSI}$ in the early stage of thyroid carcinogenesis, although it can also highlight the protective role of genetic loss in 16q21.1 against progression into FTC. The results on genetic instability in E-cadherin loci are divergent; other researchers have observed high $\mathrm{LOH}$ frequencies in this region in PTC [10, 15, 19]. However, the low LOH/MSI frequency in lesions derived from thyroid follicular cells could be explained via the alternative mechanism of E-cadherin silencing, i.e., gene promoter hypermethylation [40, 45].

Our results regarding the percentage of LOH/MSI coincidence in different loci (OFAL) support the postulation that, in the multistage model of carcinogenesis, LOH/MSI in a single locus may be a primary event in the development of various types of tumors, including the thyroid. However, only progressive accumulation of these molecular changes concerning several loci and their occurrence with other genetic and/or epigenetic disorders can lead to the development of a malignant tumor [46-49]. The frequency and the range of LOH/MSI, presented in our study as OFAL, significantly increases with tumor progression (clinical stages $\mathrm{T} 2-\mathrm{T} 3$ ), which is in concordance with the multistage model of carcinogenesis. The size of the tumor at the time of diagnosis is another important prognostic factor in the course of thyroid cancer [50, 51]. Our study revealed that the highest percentage of allele loss was correlated with the diameter of the primary tumor being $\geq 3 \mathrm{~cm}$, with a significant difference in the OFAL frequency compared with tumors $<1 \mathrm{~cm}$. OFAL was also higher with lymph node involvement (clinical stage N1). This could point to the prognostic significance of OFAL, as research carried out so far indicates a correlation between the simultaneous presence of $\mathrm{LOH}$ and/ or MSI in numerous chromosomal loci and an unfavorable clinical course. It was more frequent in primary PTC with intratumor metastasis and distant metastases from primary FTC in patients who died from PTC or FTC [10, 21, 22]. Higher FAL values can be related to worse prognosis for diffuse sclerosing variants of PTC or oncocytic and tall-cell PTC variants $[22,52]$.

We also observed high OFAL frequency in FA as well as FTC, so, as such, it could be considered a universal feature in analyzing the risk of neoplasia. In addition, OFAL can be a hallmark of the follicular phenotype that can distinguish FA and FTC from NG, and FA and FTC from PTC. It may be that OFAL analysis is beneficial for patients without a suspected tumor in FNAB (Bethesda II) but with thyrotoxic hyperactivity or for the follow-up of patients. On the other hand, detection of a relatively high OFAL value in NGs suggests the presence of genetically altered precursor cells preceding morphological changes in the thyroid gland. High OFAL in NG may result from its polyclonality and various aberrations in different nodules [53]. Given the significantly higher OFAL value in NG in relation to PTC in our study, we conclude that the co-occurrence of LOH/MSI at different loci predisposes to its recognition as a marker distinguishing benign lesions from malignant tumors. Many previous studies focused only on the smallest common deleted regions: the revealed single loci were linked to the development of FA (3p14-25, 6q24-26, 7q21.1-31.2, 10q22.2, 11p15.5, 11q23-25) or NG (2p24-25, 10q22.2) [14-18, 54, 55]. Only a few of these analyses addressed the simultaneous presence of LOH/MSI and its clinical significance. Given our results, we suggest that a higher OFAL value predisposes to mild disease outcome where oncogenic mutations are absent. On the other hand, in the context of rising OFAL tendency in FA and FTC, elevated LOH/MSI frequency in NG can be a hallmark of dedifferentiation into a follicular lesion. This requires further research, especially in patients diagnosed with thyroid proliferative changes (NG) before surgical treatment.

Interestingly, our study found a negative correlation between OFAL and age of the patient at time of diagnosis, with OFAL significantly higher in younger patients ( $<40$ years). This result is particularly valuable in terms of the usefulness of age as a prognostic factor for probability of developing a malignant neoplastic lesion in the thyroid NG [56]. We also observed a higher frequency of LOH/MSI in patients aged $<45$ years, regardless of clinical parameters [57], but these results were inconclusive. Some link greater 
age ( $>45$ years) with PTC and clinical aggressiveness of cancer; others indicate a lack of association between $\mathrm{LOH} /$ MSI and age [15, 17, 19, 58]. Several reports found younger age ( $\leq 45$ years) in PTC to be an independent predictor of lymph node metastasis [50].

The prognostic importance of OFAL in lesions derived from thyroid follicular cells in correlation with sex is also uncertain. Since thyroid cancer prognosis is worse in men than in women and FAL and OFAL frequencies were significantly higher in men in our study, this issue requires independent research in the context of sex, taking into account the advance of thyroid cancer $[50,59]$.

The usefulness of the proposed OFAL analysis can also be regarded as an addition to classical mutation analysis in PTC or FTC. According to The Cancer Genome Atlas (TCGA) study, the somatic mutation density in PTC was much lower than in the majority of cancers, with the highest density observed in melanoma and non-small-cell lung or breast cancers $[60,61]$. In that analysis, based on comprehensive multiplatform analysis of new-generation sequencing (NGS) data (on 496 PTC samples), the somatic mutation density stratified the risk of cancer recurrence, correlated with age and MACIS score (prognostic score calculation for PTC) [61]. The most frequently mutated gene in PTC is $B R A F$, accounting for almost $60 \%$ of the driver mutations. Others that are also frequently altered are NRAS, HRAS, KRAS, EIF1AX, PPMID, ZFHX3, TG, and CHEK2. These genes are localized in different genomic locations without a clear mutation hotspot [61]. Three are localized in regions analyzed in our study. HRAS is located in the region with the highest frequency of LOH/MSI observed in our study (11p15.5), but nevertheless at a distance from the microsatellite markers used for the $K C N Q 1$ cluster. Two genes mentioned in the TCGA study, in the 16q, are $C D H 1$ in $16 \mathrm{q} 22.1$ and $Z F H X 3$ near $16 \mathrm{q} 21$. The $16 \mathrm{q} 22$ region in our study was characterized by the lowest LOH/MSI frequency. A low rate of MSI is not necessarily associated with lack of mutation. Nevertheless, the evaluation of LOH/MSI markers located on different chromosomes enabled calculation of OFAL, which can be used as a simple tool to assess general instability in the genome, using much cheaper methods than NGS and not requiring complex bioinformatic analysis.

The usefulness of proposed FAL and OFAL analysis was also tested regarding the initial cytologic diagnosis of focal thyroid lesions. We evaluated the frequency of LOH/MSI in groups according to initial cytology diagnosis. Our analyses indicated that frequency of LOH/MSI does not coincide with the initial biopsy category (benign; follicular neoplasm; suspicious for malignancy; malignant). On the other hand, comparison of OFAL in each FNAB category (diagnoses confirmed vs. not confirmed) revealed significantly lower OFAL values in lesions with diagnoses confirmed by histopathology. Elevated OFAL (based on regions selected for our study) coincided with cases where the FNAB score did not coincide with the histopathology score. For example, the significantly elevated OFAL value in samples from the benign group (Bethesda II), not confirmed by histopathology, can direct attention to the presence of malignant lesions even if the FNAB result is benign. This is in accordance with our finding that the highest OFAL value was detected in FA and FTC histotypes, and that $45 \%$ of patients with an initial FNAB diagnosis of Bethesda II eventually had malignant change. However, the statistically significant relationships were not obtained for the same material; LOH/MSI was analyzed in tissue obtained after total thyroidectomy not from the biopsied nodule. An elevated frequency of LOH/MSI, despite correlation with histopathological features, does not correlate with FNAB result, which can also be due to limitations of the biopsy procedure. Using the studied tissue material rather than biopsies, it is not possible to directly translate the diagnostic value of LOH/MSI for preoperative material, but testing the frequency of LOH/MSI in selected regions in preoperative material may be useful for determining risk or analyzing ambiguous diagnoses. OFAL analysis may play a role in the evaluation of tumor progression and can probably be beneficial for patients with Bethesda II FNAB.

\section{Study Limitations}

The main limitation of our study is the small number of patients with FA and FTC because our study involved only a single center. The research material was obtained from one hospital, in which only a few such operations were conducted during the study period. For the study (from 2011 to 2016), we collected a greater proportion of FA and FTC samples than occurs in the general population compared with PTC samples: in the Polish population, the prevalence of FTC is about $8 \%$ among differentiated thyroid cancers, and the frequency of FA is about $3-4.3 \%$ (7-8\% women and $2 \%$ men) among thyroid proliferative/hyperplastic changes [62]. However, we believe our results indicating a significantly higher frequency of LOH/MSI in follicular neoplasms (FA and FTC) compared with PTC and NG are valuable and encourage further research (multicenter studies) aimed at supporting differential diagnosis of thyroid cancer based on molecular methods.

Our main research goal was assessment of the presence of LOH/MSI in thyroid cancer tissue. A comparison study involving genetic testing of (initial) biopsy material would enable us to confirm our findings on the role of OFAL in the evaluation of tumor progression. Unfortunately, we had no biopsy material on which to perform a comparative LOH/ MSI analysis to state unequivocally whether our proposed markers would be useful in the differential diagnosis of FNAB. 


\section{Conclusions}

LOH/MSI genetic instability is one of the hallmarks of multistage carcinogenesis in the thyroid gland. The results of our study indicate the importance of LOH/MSI assessment in the following chromosomal regions: 3p21.3 (statistically elevated LOH/MSI in early stages of thyroid tumors), $1 \mathrm{p} 31.2$, and $11 \mathrm{p} 15.5$ (for advanced stages). However, we would like to highlight the analysis of the LOH/MSI cooccurrence in several loci, i.e., the OFAL profile, which reflects the total level of genetic instability in cancer, leading to the development of aggressive forms and reflecting the clinical progression of neoplasm. A high OFAL frequency in thyroid tumors confirms the influence of genetic instability in various regions, affecting the loci of genes regulating the survival and growth of cancer cells. The results of our study enable us to consider OFAL as a useful and inexpensive support tool as a marker of tumor progression. In addition, future multicenter research may confirm our findings regarding OFAL as a characteristic feature of the follicular phenotype, and thus the importance of OFAL analysis as a diagnostic marker distinguishing FA and FTC from both NG and PTC.

Author contributions MMS and KHC conceived and designed the research project. MMS performed the experiments. EN conducted DNA isolation and quality assessment. MK and KK collected tissue and pathological verification of lesions derived from thyroid follicular cell. MMS and KHC conducted the data analysis. MMS, KHC, DPL, and EBL wrote the manuscript.

\section{Compliance with Ethical Standards}

Conflict of interest Monika Migdalska-Sęk, Karolina H. Czarnecka, Michał Kusiński, Dorota Pastuszak-Lewandoska, Ewa Nawrot, Krzysztof Kuzdak, and Ewa Brzeziańska-Lasota have no conflicts of interest that are directly relevant to the content of this article.

Funding This work was supported by the Grant of the Ministry of Science and Higher Education "Iuventus Plus" no 0082/IP1/2011/71 awarded to KH Czarnecka.

Open Access This article is distributed under the terms of the Creative Commons Attribution-NonCommercial 4.0 International License (http://creativecommons.org/licenses/by-nc/4.0/), which permits any noncommercial use, distribution, and reproduction in any medium, provided you give appropriate credit to the original author(s) and the source, provide a link to the Creative Commons license, and indicate if changes were made.

\section{References}

1. Kilfoy BA, Zheng T, Holford TR, Han X, Ward MH, Sjodin A, Zhang Y, Bai Y, Zhu C, Guo GL, et al. International patterns and trends in thyroid cancer incidence 1973-2002. Cancer
Causes Control. 2009;20:525-31. https://doi.org/10.1007/s1055 2-008-9260-4.

2. Lee TJ, Kim S, Cho HJ, Lee JH. The incidence of thyroid cancer is affected by the characteristics of a healthcare system. J Korean Med Sci. 2012;27:1491-8. https://doi.org/10.3346/ jkms.2012.27.12.1491.

3. Pellegriti G, Frasca F, Regalbuto C, Squatrito S, Vigneri R. Worldwide increasing incidence of thyroid cancer: update on epidemiology and risk factors. J Cancer Epidemiol. 2013;2013:965212. https://doi.org/10.1155/2013/965212.

4. Czarniecka A, Oczko-Wojciechowska M, Barczyński M. BRAF V600E mutation in prognostication of papillary thyroid cancer (PTC) recurrence. Gland Surg. 2016;5:495-505. https://doi. org/10.21037/gs.2016.09.09.

5. Vaccarella S, Franceschi S, Bray F, Wild CP, Plummer M, Dal Maso L. Worldwide thyroid cancer epidemic? The increasing impact of overdiagnosis. N Engl J Med. 2016;18:614-7. https:// doi.org/10.1056/NEJMp1604412.

6. Perros P, Boelaert K, Colley S, Evans C, Evans RM, Gerrard Ba G, Gilbert J, Harrison B, Johnson SJ, Giles TE, et al. Guidelines for the management of thyroid cancer. Clin Endocrinol (Oxf). 2014;81:1-122. https://doi.org/10.1111/cen.12515.

7. Patel HH, Goyal N, Goldenberg D. Imaging, genetic testing, and biomarker assessment of follicular cell-derived thyroid cancer. Ann Med. 2014;46:409-16. https://doi.org/10.3109/07853 890.2014.923739.

8. Nikiforov YE. Genetic alterations involved in the transition from well-differentiated to poorly differentiated and anaplastic thyroid carcinomas. Endocr Pathol. 2004;15:319-27.

9. Kondo T, Ezzat S, Asa SL. Pathogenetic mechanisms in thyroid follicular-cell neoplasia. Nat Rev Cancer. 2006;6:292-306. https ://doi.org/10.1038/nrc1836.

10. Kitamura Y, Shimizu K, Tanaka S, Ito K, Emi M. Association of allelic loss on 1q, 4p, 7q, 9p, 9q, and 16q with postoperative death in papillary thyroid carcinoma. Clin Cancer Res. 2000;6:1819-25.

11. Bauer AJ, Cavalli LR, Rone JD, Francis GL, Burch HB, Tuttle RM, Ringel MD, Stratakis CA, Haddad BR. Evaluation of adult papillary thyroid carcinomas by comparative genomic hybridization and microsatellite instability analysis. Cancer Genet Cytogenet. 2002;135:182-6.

12. Vaish M, Mishra A, Kaushal M, Mishra SK, Mittal B. Microsatellite instability and its correlation with clinicopathological features in a series of thyroid tumors prevalent in iodine deficient areas. Exp Mol Med. 2004;36:122-9. https://doi.org/10.1038/ emm.2004.18.

13. Farrand K, Delahunt B, Wang XL, McIver B, Hay ID, Goellner JR, Eberhardt NL, Grebe SK. High resolution loss of heterozygosity mapping of $17 \mathrm{p} 13$ in thyroid cancer: Hurthle cell carcinomas exhibit a small 411-kilobase common region of allelic imbalance, probably containing a novel tumor suppressor gene. J Clin Endocrinol Metab. 2002;87:4715-21. https://doi.org/10.1210/jc.2002020708 .

14. Rodrigues-Serpa A, Catarino A, Soares J. Loss of heterozygosity in follicular and papillary thyroid carcinomas. Cancer Genet Cytogenet. 2003;141:26-31.

15. Kim JH, Choi KY, Lee DJ, Rho YS, Jo SJ. Loss of heterozygosities in five tumor suppressor genes (FHIT Gene, p16, pRb, E-Cadherin and p53) in thyroid tumors. Clin Exp Otorhinolaryngol. 2014;7:53-8. https://doi.org/10.3342/ceo.2014.7.1.53.

16. Trovato M, Ulivieri A, Dominici R, Ruggeri RM, Vitarelli E, Benvenga S, Barresi G, Trimarchi F, Brunetti E, Vecchione A, et al. Clinico-pathological significance of celltype-specific loss of heterozygosity on chromosome 7q21: analysis of 318 microdissected thyroid lesions. Endocr Relat Cancer. 2004;11:365-76. 
17. Wozniak A, Wiench M, Olejniczak A, Wloch J, Lachinski A, Lange D, Olczyk T, Jarzab B, Limon J. Loss of heterozygosity in 73 human thyroid tumors. Neuro Endocrinol Lett. 2005;26:521-5.

18. Sarquis MS, Weber F, Shen L, Broelsch CE, Jhiang SM, Zedenius J, Frilling A, Eng C. High frequency of loss of heterozygosity in imprinted, compared with nonimprinted, genomic regions in follicular thyroid carcinomas and atypical adenomas. J Clin Endocrinol Metab. 2006;91:262-9. https://doi.org/10.1210/ jc.2005-1880.

19. Czarnecka K, Pastuszak-Lewandoska D, Migdalska-Sek M, Nawrot E, Brzezinski J, Dedecjus M, Pomorski L, Brzezianska E. Aberrant methylation as a main mechanism of TSGs silencing in PTC. Front Biosci (Elite ed). 2011;3:137-57.

20. Hunt JL, Livolsi VA, Baloch ZW, Swalsky PA, Bakker A, Sasatomi E, Finkelstein S, Barnes EL. A novel microdissection and genotyping of follicular-derived thyroid tumors to predict aggressiveness. Hum Pathol. 2003;34:375-80. https://doi. org/10.1053/hupa.2003.61.

21. Hunt JL, Yim JH, Carty SE. Fractional allelic loss of tumor suppressor genes identifies malignancy and predicts clinical outcome in follicular thyroid tumors. Thyroid. 2006;16:643-9. https://doi. org/10.1089/thy.2006.16.643.

22. Lin X, Finkelstein SD, Zhu B, Silverman JF. Molecular analysis of multifocal papillary thyroid carcinoma. J Mol Endocrinol. 2008;41:195-203. https://doi.org/10.1677/JME-08-0063.

23. Edge SB, Compton CC. The American Joint Committee on Cancer: the 7th edition of the AJCC cancer staging manual and the future of TNM. Ann Surg Oncol. 2010;17:1471-4. https://doi. org/10.1245/s10434-010-0985-4.

24. Kleer CG, Bryant BR, Giordano TJ, Sobel M, Merino MJ. Genetic changes in chromosomes $1 \mathrm{p}$ and $17 \mathrm{p}$ in thyroid cancer progression. Endocr Pathol. 2000;11:137-43.

25. McCarthy RP, Wang M, Jones TD, Strate RW, Cheng L. Molecular evidence for the same clonal origin of multifocal papillary thyroid carcinomas. Clin Cancer Res. 2006;12:2414-8. https:// doi.org/10.1158/1078-0432.CCR-05-2818.

26. Weber F, Aldred MA, Morrison CD, Plass C, Frilling A, Broelsch CE, Waite KA, Eng C. Silencing of the maternally imprinted tumor suppressor ARHI contributes to follicular thyroid carcinogenesis. J Clin Endocrinol Metab. 2005;90:1149-55. https://doi. org/10.1210/jc.2004-1447.

27. Dalai I, Missiaglia E, Barbi S, Butturini G, Doglioni C, Falconi $\mathrm{M}$, Scarpa A. Low expression of ARHI is associated with shorter progression-free survival in pancreatic endocrine tumors. Neoplasia. 2007;9:181-3.

28. Mao Y, Han Y, Shi W. The expression of aplysia ras homolog I (ARHI) and its inhibitory effect on cell biological behavior in esophageal squamous cell carcinoma. Onco Targets Ther. 2017;10:1217-26. https://doi.org/10.2147/OTT.S125742.

29. Marciniak M. Genotype imprinting in mammals: the latest reports. Adv Cell Biol. 2008;35:243-57.

30. Lang F, Föller M, Lang KS, Lang PA, Ritter M, Gulbins E, Vereninov A, Huber SM. Ion channels in cell proliferation and apoptotic cell death. J Membr Biol. 2005;205:147-57. https://doi. org/10.1007/s00232-005-0780-5.

31. Kitamura Y, Shimizu K, Ito K, Tanaka S, Emi M. Allelotyping of follicular thyroid carcinoma: frequent allelic losses in chromosome arms 7q, 11p, and 22q. J Clin Endocrinol Metab. 2001;86:4268-72. https://doi.org/10.1210/jcem.86.9.7853.

32. Zhang Y, Cao H, Wang M, Zhao WY, Shen ZY, Shen DP, Ni $\mathrm{XZ}$, Wu ZY, Shen YY, Song YY. Loss of chromosome 9p21 and decreased 16 expression correlate with malignant gastrointestinal stromal tumor. World J Gastroenterol. 2010;16:4716-24.

33. El-Mokadem I, Lim A, Kidd T, Garret K, Pratt N, Batty D, Fleming S, Nabi G. Microsatellite alteration and immunohistochemical expression profile of chromosome 9p21 in patients with sporadic renal cell carcinoma following surgical resection. BMC Cancer. 2016;16:546. https://doi.org/10.1186/s12885-016-2514-8.

34. Senchenko VN, Liu J, Loginov W, Bazov I, Angeloni D, Seryogin Y, Ermilova V, Kazubskaya T, Garkavtseva R, Zabarovska VI, et al. Discovery of frequent homozygous deletions in chromosome 3p21.3 LUCA and AP20 regions in renal, lung and breast carcinomas. Oncogene. 2004;23:5719-28. https://doi.org/10.1038/ sj.onc. 1207760.

35. Shivakumar L, Minna J, Sakamaki T, Pestell R, White MA. The RASSF1A tumor suppressor blocks cell cycle progression and inhibits cyclin D1 accumulation. Mol Cell Biol. 2002;22:4309-18.

36. van der Weyden L, Tachibana KK, Gonzalez MA, Adams DJ, Ng BL, Petty R, Venkitaraman AR, Arends MJ, Bradley A. The RASSF1A isoform of RASSF1 promotes microtubule stability and suppresses tumorigenesis. Mol Cell Biol. 2005;25:8356-67. https://doi.org/10.1128/MCB.25.18.8356-8367.2005.

37. Agathanggelou A, Honorio S, Macartney DP, Martinez A, Dallol A, Rader J, Fullwood P, Chauhan A, Walker R, Shaw JA, et al. Methylation associated inactivation of RASSF1A from region 3 p21.3 in lung, breast and ovarian tumours. Oncogene. 2001;20:1509-18. https://doi.org/10.1038/sj.onc.1204175.

38. Morrissey C, Martinez A, Zatyka M, Agathanggelou A, Honorio S, Astuti D, Morgan NV, Moch H, Richards FM, Kishida T, et al. Epigenetic inactivation of the RASSF1A 3p21.3 tumor suppressor gene in both clear cell and papillary renal cell carcinoma. Cancer Res. 2001;61:7277-81.

39. Xing M, Cohen Y, Mambo E, Tallini G, Udelsman R, Ladenson PW, Sidransky D. Early occurrence of RASSF1A hypermethylation and its mutual exclusion with BRAF mutation in thyroid tumorigenesis. Cancer Res. 2004;64:1664-8.

40. Hoque MO, Rosenbaum E, Westra WH, Xing M, Ladenson P, Zeiger MA, Sidransky D, Umbricht CD. Quantitative assessment of promoter methylation profiles in thyroid neoplasms. J Clin Endocrinol Metab. 2005;90:4011-8. https://doi.org/10.1210/ jc.2005-0313.

41. Migdalska-Sęk M, Pastuszak-Lewandoska D, Czarnecka K, Nawrot E, Domańska D, Brzeziński J, Dedecjus M, Brzeziańska E. Methylation profile of selected TSGs in non-cancerous thyroid tissue adjacent to primary PTC. Contemp Oncol. 2011;15:191-7.

42. Gauchotte G, Lacomme S, Brochin L, Tournier B, Cahn V, Monhoven N, Piard F, Klein M, Martinet N, Rochette-Egly C, et al. Retinoid acid receptor expression is helpful to distinguish between adenoma and well-differentiated carcinoma in the thyroid. Virchows Arch. 2013;462:619-32. https://doi.org/10.1007/s0042 8-013-1419-z.

43. Czajka AA, Wójcicka A, Kubiak A, Kotlarek M, BakułaZalewska E, Koperski $Ł$, Wiechno W, Jażdżewski K. Family of microRNA-146 regulates RAR $\beta$ in papillary thyroid carcinoma. PLoS One. 2016;11:e0151968. https://doi.org/10.1371/journ al.pone. 0151968 .

44. Andrews JL, Kim AC, Hens JR. The role and function of cadherins in the mammary gland. Breast Cancer Res. 2012;14:203-13. https://doi.org/10.1186/bcr3065.

45. Smith JA, Fan CY, Zou C, Bodenner D, Kokoska MS. Methylation status of genes in papillary thyroid carcinoma. Arch Otolaryngol Head Neck Surg. 2007;133:1006-11. https://doi.org/10.1001/ archotol.133.10.1006.

46. Maggioni M, Coggi G, Cassani B, Bianchi P, Romagnoli S, Mandelli A, Borzio M, Colombo P, Roncalli M. Molecular changes in hepatocellular dysplastic nodules on microdissected liver biopsies. Hepatology. 2000;32:942-6. https://doi.org/10.1053/ jhep.2000.18425.

47. Powell CA, Bueno R, Borczuk AC, Caracta CF, Richards WG, Sugarbaker DJ, Brody JS. Patterns of allelic loss differ in lung adenocarcinomas of smokers and nonsmokers. Lung Cancer. 2003;39:23-9. 
48. Pan H, Califano J, Ponte JF, Russo AL, Cheng KH, Thiagalingam A, Nemani P, Sidransky D, Thiagalingam S. Loss of heterozygosity patterns provide fingerprints for genetic heterogeneity in multistep cancer progression of tobacco smoke-induced nonsmall cell lung cancer. Cancer Res. 2005;65:1664-9. https://doi. org/10.1158/0008-5472.CAN-04-3297.

49. De Schutter H, Spaepen M, Mc Bride WH, Nuyts S. The clinical relevance of microsatellite alterations in head and neck squamous cell carcinoma: a critical review. Eur J Hum Genet. 2007;15:734 41. https://doi.org/10.1038/sj.ejhg.5201845.

50. Liu W, Cheng R, Su Y, Diao C, Qian J, Zhang J, Ma Y, Fan Y. Risk factors of central lymph node metastasis of papillary thyroid carcinoma: a single-center retrospective analysis of 3273 cases. Medicine (Baltimore). 2017;96:e8365. https://doi.org/10.1097/ MD.0000000000008365.

51. Nguyen XV, Roy Choudhury K, Tessler FN, Hoang JK. Effect of tumor size on risk of metastatic disease and survival for thyroid cancer: implications for biopsy guidelines. Thyroid. 2018;28:295300. https://doi.org/10.1089/thy.2017.0526.

52. Hunt JL, Fowler M, Lomago D, Niehouse L, Sasatomi E, Swalsky $\mathrm{P}$, Finkelstein S. Tumor suppressor gene allelic loss profiles of the variants of papillary thyroid carcinoma. Diagn Mol Pathol. 2004;13:41-6.

53. Führer D, Musholt T, Schmid KW. Molecular pathogenesis of thyroid nodules: relevance for clinical care. Laryngorhinootologie. 2017;96:590-6. https://doi.org/10.1055/s-0043-109180.

54. Oriola J, Halperin I, Mallofré C, Muntané J, Angel M, RiveraFillat F. Screening of selected genomic areas potentially involved in thyroid neoplasms. Eur J Cancer. 2001;37:2470-4.
55. Krohn K, Paschke R. Loss of heterozygocity at the thyroid peroxidase gene locus in solitary cold thyroid nodules. Thyroid. 2001;11:741-7. https://doi.org/10.1089/10507250152484574.

56. Luo J, McManus C, Chen H, Sippel RS. Are there predictors of malignancy in patients with multinodular goiter? J Surg Res. 2012;15:207-10. https://doi.org/10.1016/j.jss.2011.11.1035.

57. Dobosz T, Lukienczuk T, Sasiadek M, Kuczyńska A, Jankowska E, Blin N. Microsatellite instability in thyroid papillary carcinoma and multinodular hyperplasia. Oncology. 2000;58:305-10. https ://doi.org/10.1159/000012117.

58. Brzeziańska E, Migdalska-Sęk M, Cyniak-Magierska A, Koptas W, Lewiński A. Loss of heterozygosity and microsatellite instability in the 3p24.2-3pter region in papillary thyroid carcinoma. Arch Med Sci. 2007;3:192-9.

59. Giusti F, Falchetti A, Franceschelli F, Marini F, Tanini A, Brandi ML. Thyroid cancer: current molecular perspectives. J Oncol. 2010;2010:351679. https://doi.org/10.1155/2010/351679.

60. Lawrence MS, Stojanov P, Mermel CH, Robinson JT, Garraway LA, Golub TR, Meyerson M, Gabriel SB, Lander ES, Getz G. Discovery and saturation analysis of cancer genes across 21 tumour types. Nature. 2013;505:495-501. https://doi.org/10.1038/natur e12912.

61. Cancer Genome Atlas Research Network. Integrated genomic characterization of papillary thyroid carcinoma. Cell. 2014;159:676-90. https://doi.org/10.1016/j.cell.2014.09.050.

62. McHenry CR, Phitayakorn R. Follicular adenoma and carcinoma of the thyroid gland. Oncologist. 2011;16:585-93. 